\title{
A 1-year follow-up study with C-VEMPs, O-VEMPs and video head impulse testing in vestibular neuritis
}

\author{
Giuseppe Magliulo • Giannicola Iannella • \\ Silvia Gagliardi • Massimo Re
}

Received: 20 March 2014/ Accepted: 18 November 2014

(c) Springer-Verlag Berlin Heidelberg 2014

\begin{abstract}
The aim of this paper was to evaluate prospectively, in a group of patients affected by VN, a diagnostic protocol employing C-VEMPs, O-VEMPs and vHIT together. The diagnosis of vestibular neurolabyrinthitis was based on the clinical history, absence of associated auditory or neurological symptoms, and a neuro-otological examination with an evaluation of lateral semicircular canal function using the Fitzgerald-Hallpike caloric vestibular test and ice test. Our series revealed an incidence of $55 \%$ of superior and inferior vestibular neurolabyrinthitis, $40 \%$ of superior vestibular neurolabyrinthitis and $5 \%$ of inferior vestibular neurolabyrinthitis. These data, however, comprised different degrees of vestibular involvement considering the evaluation of each single vestibular end-organ with potential different prognosis. Four patients had only deficits of the horizontal and superior semicircular canals or their ampullary nerves. The implementation of C-VEMPs, O-VEMPs and vHIT in a vestibular diagnostic protocol has made possible to observe patients with ampullary VN, unidentifiable with other types of vestibular exams. The effect of age seems to have some impact on the
\end{abstract}

G. Magliulo $(\bowtie) \cdot$ G. Iannella $\cdot$ S. Gagliardi · M. Re

"Organi di Senso" Department, University "La Sapienza",

Via Gregorio VII n. 80, 00165 Rome, Italy

e-mail: giuseppemagliuloorl@yahoo.com

G. Iannella

e-mail: giannicolaiannella@ hotmail.it

S. Gagliardi

e-mail: silvia_gagliardi@hotmail.it

M. Re

e-mail: remassimo@hotmail.com

M. Re

Department of Clinical Sciences, Polytechnic University

of Marche, Rome, Italy recovery. When recovery firstly involves the utricular and saccular nerves and subsequently the ampullary nerves, it may be reasonable to expect a more favorable and successful outcome.

Keywords Vestibular neurolabyrinthitis - C-VEMPs · O-VEMPs · vHIT

\section{Introduction}

The advent of the cervical vestibular evoked myogenic potentials (C-VEMPs), of the ocular vestibular evoked myogenic potentials (O-VEMPs) and of the video head impulse test (vHIT) has provided new diagnostic tools to assess an impairment of the otolith organs and semicircular canals. Their combined use may allow a more precise differentiation of the vestibular receptor involvement in different vestibular dysfunctions [1].

One of the vestibular diseases that may benefit of a diagnostic protocol, including C-VEMPs, O-VEMPs and vHIT together, is represented by vestibular neuritis $(\mathrm{VN})$ [2-5].

There is a real interest in this specific topic evidenced by the increasing number of papers reported in the literature. Since the first small case series of Magliulo et al. [6] in 2012, Walther and Blödow [7] were able to differentiate four types of VN, i.e., entire VN, superior VN, inferior VN and ampullary $\mathrm{VN}$ employing these new diagnostic tools. Magliulo et al. [8] contemporary proposed a 6-class system of classification to categorize the various pathological findings with regard to the location of vestibular damage and the number of vestibular end-organs involved in a group of forty patients with unilateral acute $\mathrm{VN}$ followed up for 6 months. 
The aim of this paper was to assess prospectively the 1-year clinical evolution of the vestibular symptoms as well as recovery of the responses of C-VEMPs, O-VEMPs and vHIT together in a group of patients affected by unilateral acute VN. The second issue was to analyze the clinical value of the classification previously proposed in terms of prognosis.

\section{Materials and methods}

This prospective study consisted of twenty-eight patients affected by vestibular neurolabyrinthitis (mean age 42.7 years, range 10-78 years; thirteen men and fifteen women) and seen between January 2010 and Febraury 2014. The study was designed to assess the recovery of a group of patients who completed 1-year follow-up.

The patients were investigated using the same diagnostic protocol previously adopted [8]. In detail, each patient underwent Fitzgerald-Hallpike caloric vestibular test with cold $\left(30^{\circ}\right)$ and warm stimulation $\left(44^{\circ}\right)$ when spontaneous nystagmus disappeared (normal value canal paresis $<15 \%$ ) integrated by the ice test in patients with arreflexia, C-VEMPs, O-VEMPs and vHIT.

The C-VEMPs and the O-VEMPS were measured using an MK22 Amplaid and applying the same method described in detail elsewhere. Various parameters for abnormality of the C-VEMPs and O-VEMPS (the absence, the increase of latency and the decrease of the amplitude of the p1-n1 complex or of the N10 wave more than 2 standard deviations using our age-related normative reference range [9]: p1 latency normal value $16.25 \mathrm{~ms}, \mathrm{SD} 1.52$; N10 wave latency normal value $10.29 \mathrm{~ms}$, SD 0.60; p1-n1 amplitude normal value $\mu \mathrm{V}$ 39.75, SD 21.68; N10 wave amplitude normal value $6.57 \mu \mathrm{V}, \mathrm{SD} 2.01$ ) were examined. C-VEMPs were analyzed ipsilaterally, whereas O-VEMPS due to their crossed vestibulo-ocular reflex (VOR) responses were calculated on the side opposite to the ear affected by VN.

Video head impulse test was performed using the system developed and validated by Ulmer $[3,10]$ and the company Synapsis. The system consists of a low frequency camera set in front of the patient. It detects only over saccades. The responses of each of the six semicircular canals allow to calculate the VOR deficit for each semicircular canal. A difference of $\geq 40 \%$ was considered abnormal and graphically expressed by the system software as a red circle (normal value: green circle) [3, 10, 11]. It proved to be effective for identifying peripheral vestibular deficits even in patients with acute vestibular neuritis.

The statistical analysis was done using chi test and multivariate regression analysis. The investigation received prior approval by our institutional ethical committee and all persons gave their informed consent prior to their inclusion in the study.

\section{Results}

At the first control, the evaluation of each single vestibular end-organ or nerve using caloric tests, VEMPs and vHIT, showed a total deficit in eight patients $(28.5 \%)$. Four and three vestibular receptors or nerves were involved in ten and six patients, respectively. Only four patients had a selective involvement of two or of a single vestibular endorgan. The follow-up data at 1 year showed that 20 $(71.4 \%)$ patients had recovered normal values in all of the vestibular tests with regression of vestibular symptoms (Table 1). No total deficit or involvement of four and three vestibular end-organs was detected. One or two receptors remained altered in eight patients with a majority of absence of vestibular symptoms.

Video head impulse test using multivariate regression analysis resulted significantly associated with clinical symptoms. In case of a negative test patients had a halved risk of manifesting clinical symptoms (ORadj $=0.53$ ).

In a previous investigation, we propose a classification to group the various pathological findings due to the type and number of vestibular end-organs involved with potentially different prognosis. Details regarding the damage at onset and its evolution in each class are given in the Tables 2 and 3 .

The composition of the various groups was found to be statistically different between the onset and the 1-year follow-up: $\chi^{2}=32.5 ; d f=4 ; p=0.0001$.

An alteration of the C-VEMPs and O-VEMPs (class 2) was observed in two patients. They complained persistent and variable vestibular symptoms. The remaining six patients belonged to class 4 . This class categorizes the partial superior vestibular nerve deficit. Note that only two patients had abnormal O-VEMPs, sign of an involvement of the utricular compartment. vHIT showed an abnormality of the horizontal and superior semicircular canals or their ampullary nerves in four patients (14.2\%). Mild instability persisted in four class 4 patients.

No class 1, 3, 5 and 6 were detected at the last followup.

\section{Discussion}

In recent years, the study of the otolithic function has been remarkably benefited by the introduction of the VEMPs. These potentials are able to identify deficit of both saccular and utricular partition of the otolithic compartment [12, 13]. There is a general agreement that C-VEMPs reflect 
Table 1 Vestibular testing data at 1-year follow-up
$A$ absent, $P$ pathological,

$N$ normal, $D$ deficit, $C P$ canal paresis

\begin{tabular}{|c|c|c|c|c|c|c|c|}
\hline $\begin{array}{l}\text { No.; age } \\
\text { (years) }\end{array}$ & Symptoms & $\begin{array}{l}\text { Caloric } \\
\text { test }\end{array}$ & $\begin{array}{l}\text { O-VEMPs (Lat/ } \\
\text { Amp) }\end{array}$ & $\begin{array}{l}\text { vHIT } \\
\text { HSC }\end{array}$ & $\begin{array}{l}\text { vHIT } \\
\text { SSC }\end{array}$ & $\begin{array}{l}\text { C-VEMPs (Lat/ } \\
\text { Amp) }\end{array}$ & $\begin{array}{l}\text { vHIT } \\
\text { PSC }\end{array}$ \\
\hline $1 ; 55$ & Present & CP $43 \%$ & A & $\mathrm{N}$ & $\mathrm{N}$ & A & $\mathrm{N}$ \\
\hline $2 ; 39$ & Present & N $13 \%$ & A & $\mathrm{N}$ & $\mathrm{N}$ & A & $\mathrm{N}$ \\
\hline $3 ; 51$ & Present & $\mathrm{CP} 40 \%$ & A & $\mathrm{N}$ & $\mathrm{N}$ & $\mathrm{N}$ & $\mathrm{N}$ \\
\hline $4 ; 66$ & Absent & $\mathrm{N}$ & $\mathrm{N}$ & $\mathrm{N}$ & $\mathrm{N}$ & $\mathrm{N}$ & $\mathrm{N}$ \\
\hline $5 ; 30$ & Absent & $\mathrm{N}$ & $\mathrm{N}$ & $\mathrm{N}$ & $\mathrm{N}$ & $\mathrm{N}$ & $\mathrm{N}$ \\
\hline $6 ; 41$ & Absent & $\mathrm{N}$ & $\mathrm{N}$ & $\mathrm{N}$ & $\mathrm{N}$ & $\mathrm{N}$ & $\mathrm{N}$ \\
\hline $7 ; 35$ & Absent & N $13 \%$ & $\mathrm{~N}$ & $\mathrm{~N}$ & $\mathrm{~N}$ & $\mathrm{~N}$ & $\mathrm{~N}$ \\
\hline $8 ; 27$ & Absent & $\mathrm{N}$ & $\mathrm{N}$ & $\mathrm{N}$ & $\mathrm{N}$ & $\mathrm{N}$ & $\mathrm{N}$ \\
\hline $9 ; 53$ & Absent & $\mathrm{N}$ & $\mathrm{N}$ & $\mathrm{N}$ & $\mathrm{N}$ & $\mathrm{N}$ & $\mathrm{N}$ \\
\hline $10 ; 17$ & Absent & $\mathrm{N}$ & $\mathrm{N}$ & $\mathrm{N}$ & $\mathrm{N}$ & $\mathrm{N}$ & $\mathrm{N}$ \\
\hline $11 ; 35$ & Absent & CP $32 \%$ & $\mathrm{~N}$ & $\mathrm{~N}$ & $\mathrm{~N}$ & $\mathrm{~N}$ & $\mathrm{~N}$ \\
\hline $12 ; 72$ & Absent & CP $56 \%$ & $\mathrm{~N}$ & $\mathrm{P}$ & $\mathrm{P}$ & $\mathrm{N}$ & $\mathrm{N}$ \\
\hline $13 ; 46$ & Absent & CP $45 \%$ & $\mathrm{~N}$ & $\mathrm{~N}$ & $\mathrm{~N}$ & $\mathrm{~N}$ & $\mathrm{~N}$ \\
\hline $14 ; 29$ & Absent & CP $38 \%$ & $\mathrm{~N}$ & $\mathrm{~N}$ & $\mathrm{~N}$ & $\mathrm{~N}$ & $\mathrm{~N}$ \\
\hline $15 ; 10$ & Absent & $\mathrm{N}$ & $\mathrm{N}$ & $\mathrm{N}$ & $\mathrm{N}$ & $\mathrm{N}$ & $\mathrm{N}$ \\
\hline $16 ; 53$ & Absent & $\mathrm{N}$ & $\mathrm{N}$ & $\mathrm{N}$ & $\mathrm{N}$ & $\mathrm{N}$ & $\mathrm{N}$ \\
\hline $17 ; 31$ & Absent & СР $48 \%$ & $\mathrm{~N}$ & $\mathrm{P}$ & $\mathrm{P}$ & $\mathrm{N}$ & $\mathrm{N}$ \\
\hline $18 ; 29$ & Absent & N $13 \%$ & $\mathrm{~N}$ & $\mathrm{~N}$ & $\mathrm{~N}$ & $\mathrm{~N}$ & $\mathrm{~N}$ \\
\hline $19 ; 35$ & Absent & N $14 \%$ & $\mathrm{~N}$ & $\mathrm{~N}$ & $\mathrm{~N}$ & $\mathrm{~N}$ & $\mathrm{~N}$ \\
\hline $20 ; 46$ & Absent & $\mathrm{N}$ & $\mathrm{N}$ & $\mathrm{N}$ & $\mathrm{N}$ & $\mathrm{N}$ & $\mathrm{N}$ \\
\hline $21 ; 30$ & Absent & N $7 \%$ & $\mathrm{~N}$ & $\mathrm{~N}$ & $\mathrm{~N}$ & $\mathrm{~N}$ & $\mathrm{~N}$ \\
\hline $22 ; 58$ & Absent & $\mathrm{N}$ & $\mathrm{N}$ & $\mathrm{N}$ & $\mathrm{N}$ & $\mathrm{N}$ & $\mathrm{N}$ \\
\hline $23 ; 78$ & Absent & CP $33 \%$ & $\mathrm{~N}$ & $\mathrm{P}$ & $\mathrm{P}$ & $\mathrm{N}$ & $\mathrm{N}$ \\
\hline $24 ; 65$ & Absent & $\mathrm{N}$ & $\mathrm{N}$ & $\mathrm{N}$ & $\mathrm{N}$ & $\mathrm{N}$ & $\mathrm{N}$ \\
\hline $25 ; 27$ & Absent & N $12 \%$ & $\mathrm{~N}$ & $\mathrm{~N}$ & $\mathrm{~N}$ & $\mathrm{~N}$ & $\mathrm{~N}$ \\
\hline $26 ; 64$ & Present & CP $47 \%$ & $\mathrm{~N}$ & $\mathrm{P}$ & $\mathrm{P}$ & $\mathrm{N}$ & $\mathrm{N}$ \\
\hline $27 ; 43$ & Absent & $\mathrm{N}$ & $\mathrm{N}$ & $\mathrm{N}$ & $\mathrm{N}$ & $\mathrm{N}$ & $\mathrm{N}$ \\
\hline $28 ; 33$ & Present & $\mathrm{N}$ & A & $\mathrm{N}$ & $\mathrm{N}$ & $\mathrm{N}$ & $\mathrm{N}$ \\
\hline
\end{tabular}

Table 2 Classification of $\mathrm{VN}$ at onset

\begin{tabular}{llll}
\hline Class & Type of vestibular neurolabyrinthitis & No. of pts (case no. Table 1) & $\%$ \\
\hline 1 & Total vestibular neurolabyrinthitis (superior + inferior vestibular neuritis) & $8(1,2,8,9,10,13,19,23)$ \\
2 & $\begin{array}{l}\text { Superior vestibular neurolabyrinthitis (utricular and/or HSC and/or SSC) and inferior } \\
\text { vestibular neurolabyrinthitis (saccular and/or PSC) }\end{array}$ & $10\left(3,5^{\mathrm{a}}, 11,12,15,18^{\mathrm{a}}, 21,22,27,28\right)$ & 28.5 \\
& Total superior vestibular neurolabyrinthitis (utricular + HSC +SSC) & $6(4,6,16,17,20,26)$ & 21.4 \\
3 & Partial superior vestibular neurolabyrinthitis (utricular and/or HSC and/or SSC) & $4\left(7^{\mathrm{a}}, 14,24,25\right)$ & - \\
4 & Total inferior vestibular neurolabyrinthitis (saccular + PSC) & - & - \\
6 & Partial inferior vestibular neurolabyrinthitis (saccular and/or PSC) & - & - \\
\hline
\end{tabular}

HSC horizontal semicircular canal, SSC superior semicircular canal, PSC posterior semicircular canal

${ }^{\text {a }}$ Patients only with involvement of the ampullary end-organs or the ampullary nerves

saccular macula and nerve function. Although the origin of O-VEMPs is still a source of debate on the definite role of the utricular versus saccular fibers $[7,14,15]$, the results of numerous other investigations seem to confirm their ability to assess or to detect deficits in its utricular components in a similar manner to the caloric response for the horizontal semicircular canal $[7,15]$. Thus, both VEMPs represent a diagnostic revolution of vestibular testings providing to the otologists and neurotologists, a reliable tool to study the otolith organs and to differentiate utricular and saccular functions.

Video head impulse test has had a similar impact. It has provided essential and significantly better information on the function of semicircular canal vestibular end-organs 
Table 3 Classification of VN at 1-year follow-up

\begin{tabular}{|c|c|c|c|}
\hline Class & Type of vestibular neurolabyrinthitis & 1-year control (case no. Table 1) & $\%$ \\
\hline 0 & Normal & $\begin{array}{l}20(4,5,6,7,8,9,10,11,13,14,15,16,18, \\
\quad 19,20,21,22,24,25,27)\end{array}$ & 71.4 \\
\hline 1 & Total vestibular neurolabyrinthitis (superior + inferior vestibular neuritis) & - & - \\
\hline 2 & $\begin{array}{l}\text { Superior vestibular neurolabyrinthitis (utricular and/or HSC and/or SSC) and inferior } \\
\text { vestibular neurolabyrinthitis (saccular and/or PSC) }\end{array}$ & $2(1,2)$ & 7.1 \\
\hline 3 & Total superior vestibular neurolabyrinthitis (utricular + HSC +SSC) & - & - \\
\hline 4 & Partial superior vestibular neurolabyrinthitis (utricular and/or HSC and/or SSC) & $6\left(3,12^{\mathrm{a}}, 17^{\mathrm{a}}, 23^{\mathrm{a}}, 26^{\mathrm{a}}, 28\right)$ & 21.4 \\
\hline 5 & Total inferior vestibular neurolabyrinthitis (saccular + PSC) & - & - \\
\hline 6 & Partial inferior vestibular neurolabyrinthitis (saccular and/or PSC) & - & - \\
\hline
\end{tabular}

$H S C$ horizontal semicircular canal, SSC superior semicircular canal, PSC posterior semicircular canal

${ }^{a}$ Patients only with involvement of the ampullary end-organs or the ampullary nerves

(superior, posterior and horizontal) and ampullary nerves as well as the pathway of VOR with respect to the clinical impulse head test [8]. This test evaluates parts of the angular VOR different from those explored by caloric test using a high-frequency stimulus as demonstrated by the study of Zellhuber et al. [16].

The clinical use of both VEMPs and vHIT has modified our knowledge in several vestibular diseases [2-5].

In VN, VEMPs gave the new evidence-based concept of the possibility to diagnose partial neuritis. The series of Murofushi et al. [17] VN detecting the absence of C-VEMPs and normal caloric tests in $34 \%$ of their patients first postulated the development of inferior vestibular neuritis. Since then numerous investigations have been reported on this topic confirming the ability of the $\mathrm{C}$ - and O-VEMPs to differentiate total, superior and inferior vestibular neuritis.

Halmagyi et al. [18] suggested a selective loss of inferior vestibular nerve function reporting two patients with isolated posterior semicircular canal deficit at HIT. Schmid-Priscoveanu et al. [19] had similar findings in acute $\mathrm{VN}$ and reported a higher sensitivity of HIT in chronic patients. Other investigators using vHIT confirmed these observations describing isolated functional losses of the horizontal, posterior or superior vestibular neuritis [20-22]. However, the majority of these studies used the VEMPs and vHIT singularly and not together. Few investigations combined these tools in the evaluation of the VN. In a small series, Magliulo et al. [6] using a battery test including VEMPs and vHIT together reported the clinical suspicion of selective damage of the lateral semicircular canal receptor or superior semicircular canal receptor and the respective ampullary nerves in patients affected by VN. In 2013, Walther and Blödow [7] using the same diagnostic protocol in twenty patients were able to clinically differentiate a fourth type of $\mathrm{VN}$, the ampullary $\mathrm{VN}$, over the classic total, superior and inferior types. A contemporary study of Magliulo et al. [8] studying a series of forty patients followed up 6 months, confirmed the ampullary nerve $\mathrm{VN}$ and further differentiated this type of $\mathrm{VN}$ in that involving the afferents of the superior vestibular nerve from those of inferior vestibular nerve and extending the concept of superior or inferior $\mathrm{VN}$ to that of utricular, saccular and horizontal, superior and posterior ampullary VN. They introduced a six class classification system with different patterns of recovery and prognosis, and, finally they proposed a rehabilitation program based upon this classification.

The present investigation was specifically designed to examine the same diagnostic protocol in a group of patients affected by VN comparing the findings at onset of the disease and their eventual recovery at 1 -year follow-up. Interpretation of the reported data made it possible to confirm the diagnosis of ampullary $\mathrm{VN}$ otherwise impossible only using the traditional caloric tests. All of them recovered completely (class 0 ). The clinical evolution of the total and superior VN (Class 1-3) showed that $28.6 \%$ of these patients did not recover and the persistent deficit of O-VEMPs complained the worse symptomatology. Not surprisingly the patients belonging to class 4 with persistent deficit of the ampullary compartments had the better findings in terms of symptoms. The result of the caloric testings, well accepted sign of an abnormal function of the horizontal semicircular canal function, did not completely mirror those of vHIT. In fact, in some of these patients, the final outcome resulted normal. This datum confirms that the different frequency of stimulus of these two types of testing analyses results in different aspects of the angular VOR [16]. The new vHIT (otometric) using a small lightweight, high-speed digital video camera is a system designed to identify both the saccades (over saccades and cover saccades). Despite we used vHIT with low frequency camera that detects only over saccades, relevant data emerged. The findings of our study have influenced the vestibular rehabilitation therapy 
program administered to the VN patients. We include only exercises at home for the patients belonging to classes 4 taken into consideration that $100 \%$ of these patients recovered normal findings. The classical supervised approach where the patient works under a physical therapist's control in addition to home exercises [23, 24] should address all of the patients belonging to classes 1, 2 and 3 .

\section{Conclusion}

1. VEMPs and vHIT were confirmed as valid diagnostic tools for diagnosing selective damage of the vestibular nerve in patients affected by VN.

2. Their implementation in a vestibular diagnostic protocol has made it possible to observe patients with ampullary $\mathrm{VN}$, unidentifiable with other types of vestibular exams.

3. The classification system proposed confirmed the delayed recovery times of the superior VN. Further, it helped to monitor the modality of recovery in $\mathrm{VN}$. When recovery firstly involves the utricular and saccular nerves and subsequently the ampullary nerves, it may be reasonable to expect a more favorable and successful outcome.

4. The effect of age seems to have some impact on the recovery.

Conflict of interest The authors declare that they have no conflict of interest.

\section{References}

1. Magliulo G, Gagliardi M, Appiani GC, D'Amico R (2003) Preservation of the saccular nerve and of the vestibular evoked myogenic potential during vestibular schwannoma surgery. Otol Neurotol 24:308-311

2. Aw ST, Fetter M, Cremer PD, Karlberg M, Halmagyi GM (2001) Individual semicircular canal function in superior and inferior vestibular neuritis. Neurology 11(57):768-774

3. Ulmer E, Bernard-Demanze L, Lacour M (2011) Statistical study of normal canal deficit variation range. Measurement using the head impulse video system. Eur Ann Otorhinolaryngol Head Neck Dis 128:278-282

4. Govender S, Rosengren SM, Colebatch JG (2011) Vestibular neuritis has selective effects on air- and bone-conducted cervical and ocular vestibular evoked myogenic potentials. Clin Neurophysiol 122:1246-1255

5. Shin BS, Oh SY, Kim JS, Kim TW, Seo MW, Lee H, Park YA (2012) Cervical and ocular vestibular-evoked myogenic potentials in acute vestibular neuritis. Clin Neurophysiol 123:369-375 Epub 19 Jul 2011

6. Magliulo G, Gagliardi S, Appiani MC, Iannella G, Gagliardi M (2012) Selective vestibular neurolabyrinthitis of the lateral and superior semicircular canals and ampullary nerves. Ann Otol Rhinol Laryngol 121:640-644
7. Walther LE, Blödow A (2013) Ocular vestibular evoked myogenic potential to air conducted sound stimulation and video head impulse test in acute vestibular neuritis. Otol Neurotol 34:1084-1089

8. Magliulo G, Gagliardi S, Appiani MC, Iannella G, Re M (2014) Vestibular Neurolabyrinthitis: a follow-up study with cervical and ocular vestibular evoked myogenic potentials and the video head impulse test. Ann Otol Rhinol Laryngol 123:162-173

9. Kim HA, Hong JH, Lee H, Yi HA, Lee SR, Jang BC, Ahn BH, Baloh RW (2008) Otolith dysfunction in vestibular neuritis. Neurology 70:449-453

10. Ulmer E, Chays A (2005) Curthoys and Halmagyi head impulse test: an analytical device. Ann Otolaryngol Chir Cervicofac 122:84-90

11. Leveque M, Seiderman L, Tran H, Langagne T, Ulmer E, Chays A (2010) Vestibular function outcomes after vestibular neurectomy in Meniere disease:can vestibular neurectomy provide complete vestibular deafferentation? Auris Nasus Larynx 37:308-313

12. Magliulo G, Cuiuli G, Gagliardi M, Ciniglio-Appiani G, D'Amico R (2004) Vestibular evoked myogenic potentials and glycerol testing. Laryngoscope 114:338-343

13. Magliulo G, Cianfrone G, Gagliardi M, Cuiuli G, D'Amico R (2004) Vestibular evoked myogenic potentials and distortionproduct otoacoustic emissions combined with glycerol testing in endolymphatic hydrops: their value in early diagnosis. Ann Otol Rhinol Laryngol 113:1000-1005

14. Magliulo G, Parrotto D, Cuiuli G, Alla FR, Gagliardi M (2007) Preservation of vestibular evoked myogenic potentials with modified translabyrinthine approach. Arch Otolaryngol Head Neck Surg 133:720-723

15. Welgampola MS, Carey JP (2010) Waiting for the evidence: VEMP testing and the ability to differentiate utricular versus saccular function. Otolaryngol Head Neck Surg 143:281-283

16. Zellhuber S, Mahringer A, Rambold HA (2014) Relation of video-head-impulse test and caloric irrigation: a study on the recovery in unilateral vestibular neuritis. Eur Arch Otorhinolaryngol 271:2375-2383

17. Murofushi T, Iwasaki S, Ushio M (2006) Recovery of vestibularevoked myogenic potentials after vertigo attack due to vestibular neuritis. Acta Otolaryngol 126:364-367

18. Halmagyi GM, Karlberg M, Curthoys IS, Todd MJ (2002) Inferior vestibular neuritis. Ann N Y Acad Sci 956:306-313

19. Schmid-Priscoveanu A, Bohmer A, Obzim H, Straumann D (2001) Caloric and search-coil head-impulse testing in patients after vestibular neuritis. JARO 2:72-78

20. D'Onofrio F (2013) Vertical eye movements during horizontal head impulse test: a new clinical sign of superior vestibular neuritis. Acta Otorhinolaryngol Ital 33:418-424

21. Manzari L, Burgess AM, MacDougall HG, Curthoys IS (2013) Vestibular function after vestibular neuritis. Int $\mathrm{J}$ Audiol. 52:713-718

22. Bartolomeo M, Biboulet R, Pierre G, Mondain M, Uziel A, Venail $F$ (2014) Value of the video head impulse test in assessing vestibular deficits following vestibular neuritis. Eur Arch Otorhinolaryngol 271:681-688

23. Eleftheriadou A, Skalidi N, Velegrakis GA (2012) Vestibular rehabilitation strategies and factors that affect the outcome. Eur Arch Otorhinolaryngol 269:2309-2316

24. Han BI, Song HS, Kim JS (2011) Vestibular rehabilitation therapy: review of indications mechanisms, and key exercises. J Clin Neurol 7:184-196 